\title{
THE METHY PORTAGE - PROPOSAL FOR A SASKATCHEWAN HISTORIC AND NATURE TRAIL
}

by Henry T. Epp and Tim Jones, Department of Anthropology and Archaeology, University of Saskatchewan, Saskatoon

Methy Lake, La Loche Lake, Lac La Loche, Methy Portage, Portage La Loche-all of these are variant names for two geographical features found in the northwest-central portion of Saskatchewan (see maps). These two features are a lake and a long portage both of which bore a great deal of the early traffic in furs and European trade goods that passed through the whole of the American and Canadian northwest from the last decade or so of the 18th century into even the first few years of the present one. Today the portage is more frequently called the Clearwater Portage or the Clearwater River Portage by the residents of the La Loche area.

\section{The History of the Portage}

The importance of the Methy Portage during the Fur Trade period of Canada's history was great in comparison to various other portages because it was the shortest possible route crossing the height of land dividing the vast drainage basins of the Churchill 'River system, which empties its waters ultimately into Hudson Bay, and the Athabasca-Mackenzie drainage system, which flows into the Arctic Ocean. As such, it was the trail along which traders and trappers had to travel to get into or out of the Athabasca district. And it was truly a road in the later days, when ox-drawn Red River carts were used to haul goods north from La Loche and furs back south to this settlement (Ells 1936).

On July 14, 1968, we set out on foot from the northern shore of Lac La Loche to walk the approximately $12 \frac{1}{2}$ mile-long portage between the lake and the Clearwater River, with the major purpose in mind of examining the archaeological potentialities of the area, with special attention paid to establishing what sorts of use were made of the portage and what sorts of human occupation of the La Loche area (if any) occurred in periods of the past more distant than the obviously busy early historic period (Turner 1943). The information collected in the few days we were able to spend in the area indicates that artifactual material representing the Fur Trade or "proto-historic" period

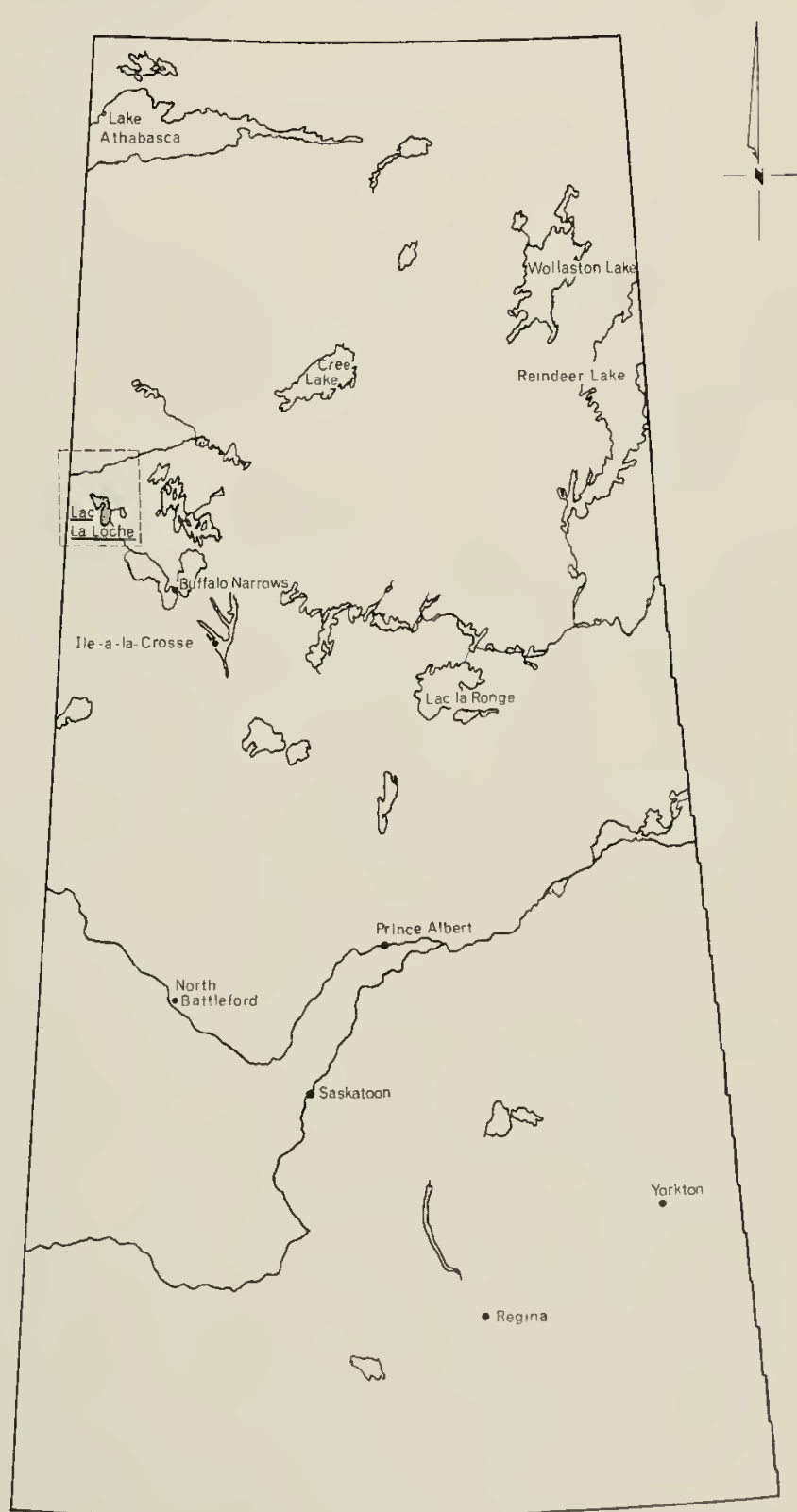




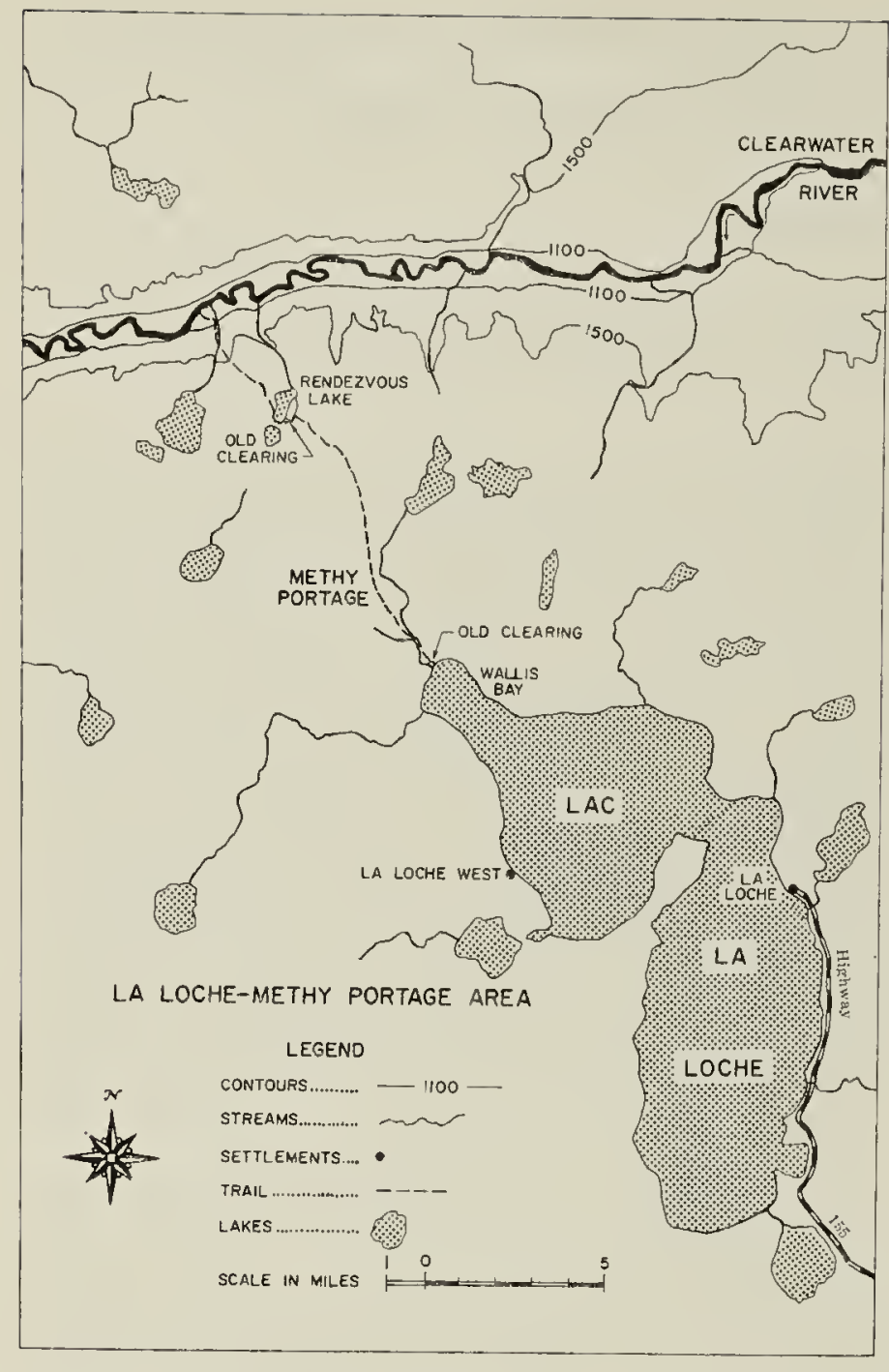

is abundant, and that other material goes back at least to Besant Culture times, approximately 2,000 years ago (Wettlaufer 1955).

This shows that the La Loche area was inhabited long before the fur traders and adventurers made use of the lake and portage, and it is highly likely that the portage was used by prehistoric populations as a trail or canoe portage for several thousand years before it became the important commercial route it was during historic times. Prehistory in this part of Saskatchewan, of course, ends in the year 1778, when Peter Pond, supposedly the first white man in the area (or at least the first one known to record his travels here), passed over the portage to explore the fur trading possibilities in the Athabasca region. The fact is that most of the fur traders and "discoverers" followed only the already well-established routes of travel developed over the centuries by aboriginal experimentation and use, and in the company of Indian guides. The aboriginal inhabitants of the continent naturally followed the course of least resistance in their travels, and, considering the length of the Methy Portage and the drop in elevation from the height of land, this portage certainly fits this category. The footing on the trail is level and sure, for the most part it most certainly is not in many places near or off the trail.

\section{The Area Today}

It is premature to discuss the archaeological aspects of the Methy Portage area, and this is not the purpose of this article. Rather, it is to discuss in more general terms what is a too-little-known region of our province. From a natural history and human standpoint, the La Loche area deserves much more attention from the residents of southern Saskatchewan than it has received up to the present day. Now that the village of La Loche is accessible from the south by automobile, it is surprising to find, from conversations with the local people, that there are as yet only sporadic tourist and other visits from the south. The 1,400 or so people of La Loche are mainly Chipewyan Indians and Metis, and their old huntingtrapping type of existence is now rapidly changing. It is being replaced by something of which no one knows the ultimate significance, including the inhabitants thenselves, let alone the people of the rest of the province (see Handley 1968).

\section{The Portage Today}

By itself the Methy Portage is one of the most spectacular and interesting trails in all of Saskatchewan as far as nature and history are concerned. About two miles from the north end of the portage one gets one's first view of the Clearwater River valley, an enormous glacial meltwater channel. This, not to mention the numerous lakes and varied forest and animal life in the area which are characteristic of the general scenery of northern Saskatche- 


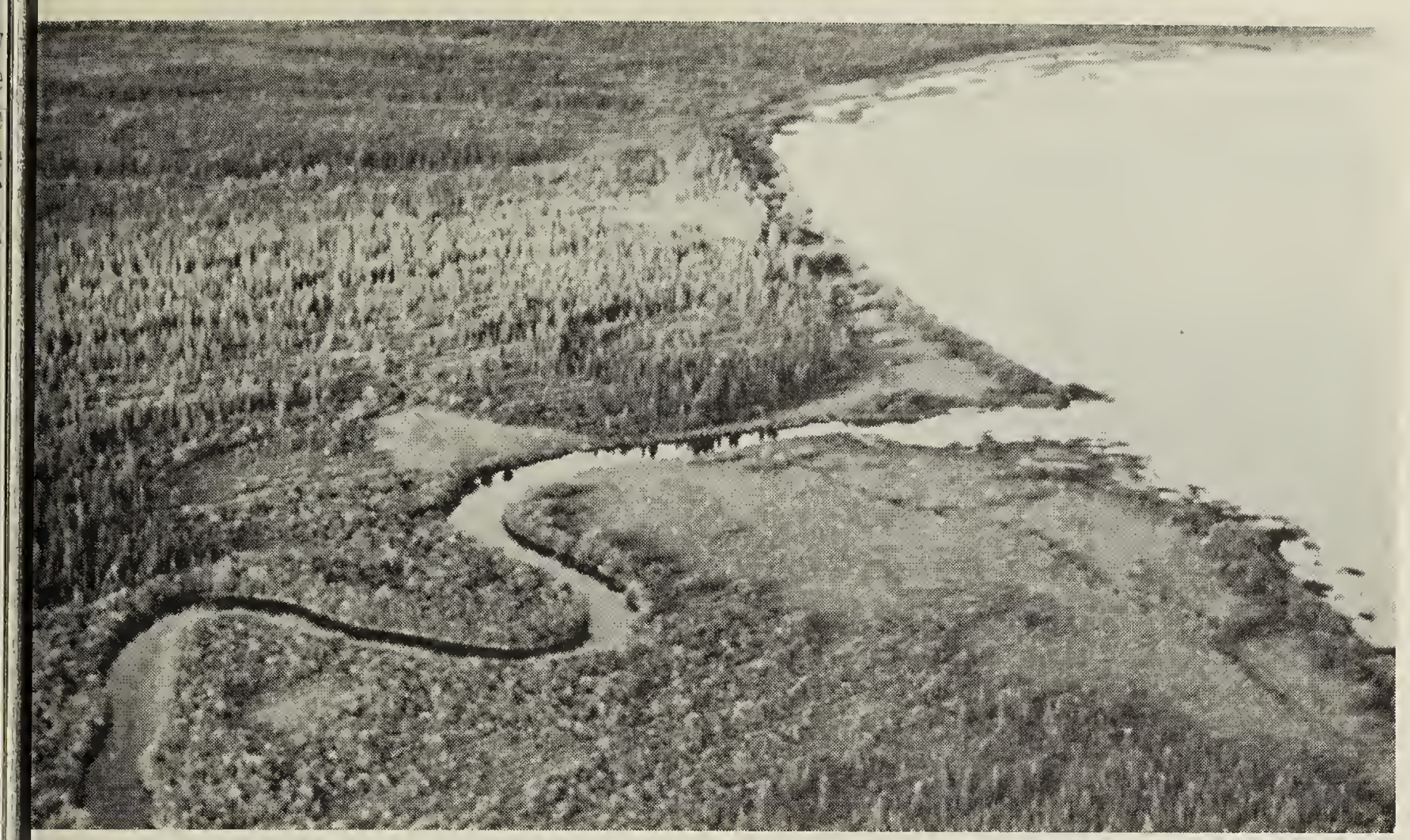

Fig. 1. Aerial view of La Loche Creek, emptying into Wallis Bay. The south end of Methy Portage begins across the creek at the first bend.

wan, is a spot which offers some of the most breathtaking scenery in the province.

The trail begins at a large, grassy clearing approximately two acres in extent, about 70 yards upstream on the northeast side of La Loche Creek, which empties into Wallis Bay, the northwestern part of Lac La Loche (Fig. 1). The trail leads north from there into a swampy area where one sinks almost knee-deep into muck or moss if one wanders off the trail. This part of the trail is nearly overgrown with low, scrubby bushes, along with small, thin spruce and a few tamarack or larch trees scattered rather infrequently throughout the area. After a quarter-mile or so it leaves the swamp and enters an area of sandy ridges covered chiefly with mature, widely-spaced jack pine, and other vegetation generally associated with such a forest. There was some evidence of recent logging or logcutting. Moose tracks and droppings were visible along much of the swampy section of the trail and the first part of the trail leading through the sand ridges, probably because of the proximity of the lake.
The trail is in fairly regular use by Chipewyan hunters and trappers and their dogs, both in winter and summer, although there is no evidence of recent wheeled traffic. In summer, it forms a route of travel for moose hunters from La Loche and West La Loche to the good hunting grounds along the Clearwater River, and in winter it forms a useful trail for trappers with their dog teams, for in most places it is wide enough to permit the passage of a good-sized sled or toboggan.

The portage crosses La Loche Creek nearly a mile upstream, where one walks over a convenient beaver dam, and then it crosses another small stream coming in from the west, about another mile up. This latter stream appears to be the only available drinking water for about the next six miles, where Rendezvous Lake is reached. From this stream bed on, the ground is extremely sandy for about two miles, and then two low-lying, swampy sections are passed through in fairly quick succession. Strangely enough, the vegetation of these swampy areas seems to be no different from that of the sand ridges south- 
east of them - fairly thin, but with tall and uniform jack pine representing the dominant vegetation, with a scattering of aspen and paper birch of about the same size growing among them. Perhaps this is due, at least in part, to the fact that the soil of these swampy areas is as sandy as that of the ridges (Fig. 2).

About seven miles up the trail the vegetation type changes to one in which the dominant tree is aspen, and a mile or so farther up it changes to a mature jack pine forest in which the trees are large and rather widely spaced. It is in such a forest that the large opening formed by what is left of the old campground on the southeastern shore of Rendezvous Lake occurs.

The lake itself is small, being less than a mile in diameter. According to Ells (1936), this was where the traders from the north and from the south and east met, exchanged their goods (furs from the north, supply and trade goods from the south), and went their separate ways - hence the name, Rendezvous Lake (Fig. 3). Looking at the map, this may seem like an extremely unfair division of

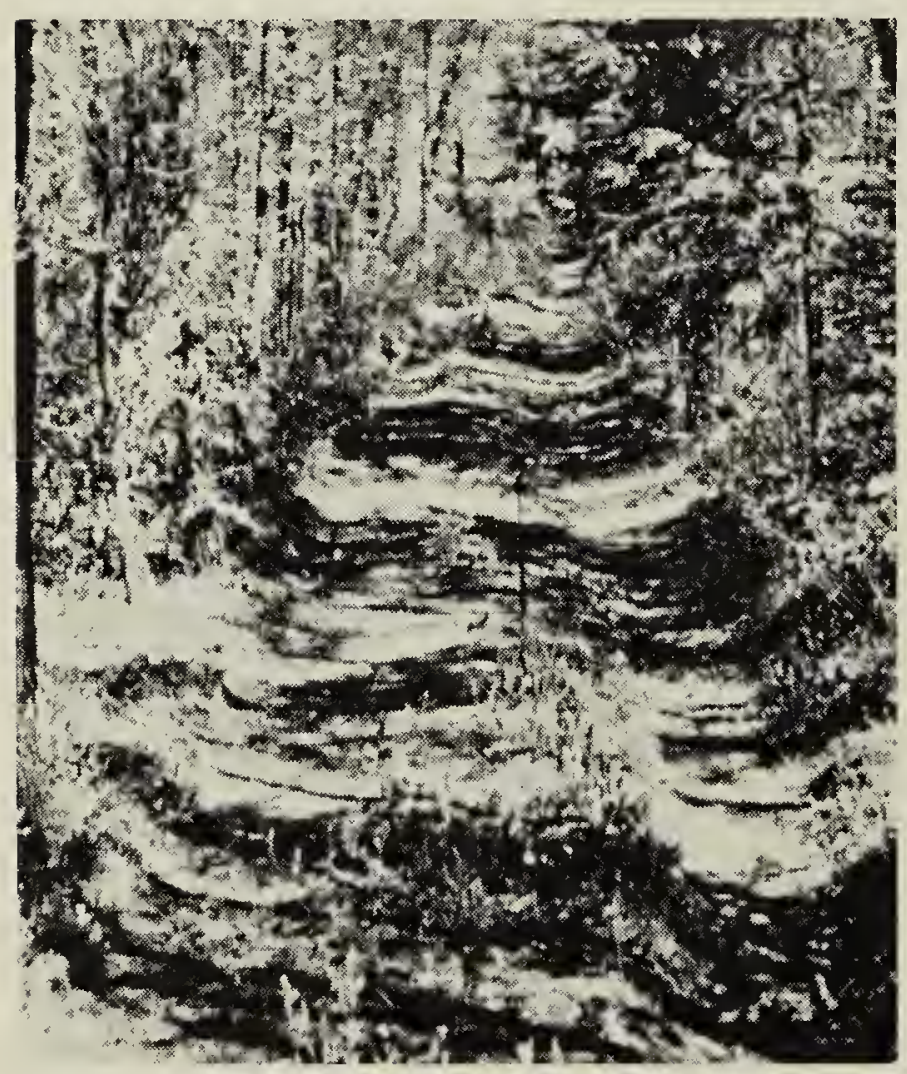

Fig. 2. The double ruts of the ox-carts may sitill be seen in some sections of the portage, especially in swampy areas. labor as far as the southern crews were concerned, since they had to carry their loads over eight miles instead of four to five miles, which was the case for the northern crews. But the northern four or five miles involve a considerable climb from the Clearwater River and are much more difficult than the southern eight miles.

From the campground on the lake the trail winds its way along old sandy beaches to the western shore of the lake and then strikes off northwestward to the Clearwater River. It rises for about two miles and then reaches the height of land, the elevation of which is about 1690 feet (Ells 1936). The descent from here is gradual at first, leading through vegetation and sandy ridges similar to those southeast of Rendezvous Lake. Suddenly it approaches a nearly vertical escarpment just to the left of the trail. From the top of this escarpment one of the most spectacular views in all of Saskatchewan presents itself. The entire Clearwater valley, more than two miles wide, is visible at this point (Fig. 4). The view in summer is one of an intense green, both from the forests, which cover most of the terrain, and from the grassy meadows visible on the high, hogsback-like, rolling banks on the north side of the river, where, according to Alexander Mackenzie, buffalo and "elk" grazed in large herds when he passed through. Mackenzie, great traveller that he was, considered this to be one of the most beautiful views he had ever seen, a scene of which he said he could not "give an adequate description."

From this point onward the portage winds downward along the steep slopes, and at one point it follows the small, but steep and slippery bed of a stream which runs rapidly down the slope. The forest here is different from that of the sandy ridges south of the escarpment. Everywhere there is evidence of former logging activity, with the trunks of large spruce lying scatteed in all directions. The forest does not now consist of spruce, however, but mainly of second-growth, spindly 


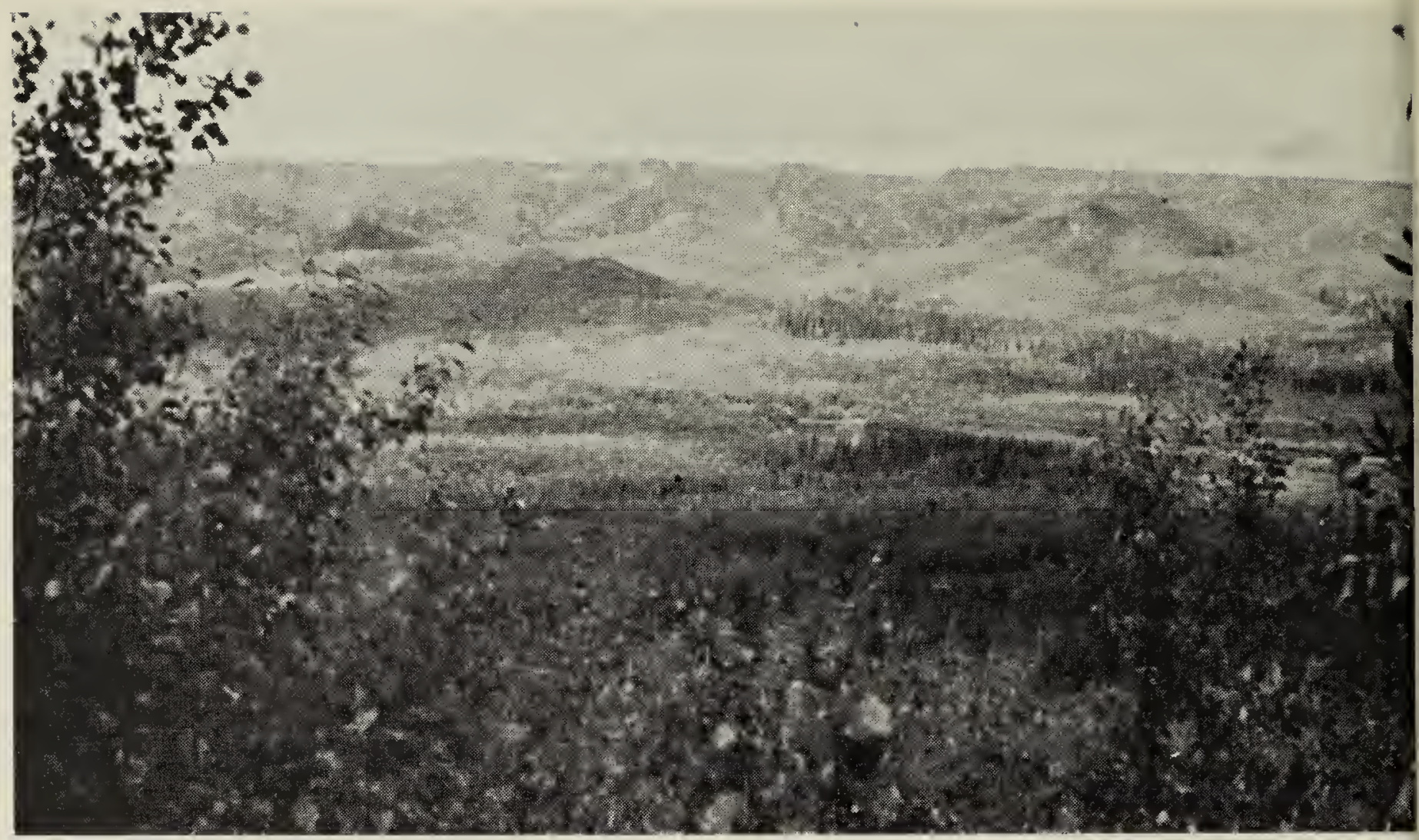

Fig. 4. The Clearwater River and its glacial valley is first seen from the portage about two miles from the north end.

esting, and beautiful vegetation and spectacular scenery is undoubtedly the four or five miles between Rendezvous Lake and the Clearwater River.

Birds were continually in evidence on the lakes and all along the trail. On Lac La Loche itself, water birds were abundant, and among those seen and identified were Canvasback and White-winged Scoter ducks, White Pelicans, Common Loons, Franklin's Gulls, and a large white gull which was not identified as to species. Spruce Grouse were extremely common along the trail, and usually did not fly far when flushed.

The small Rendezvous Lake was always full of birds, including all of the above-named water birds except pelicans. Common Terns were abundant and so were various species of ducks, including the Bufflehead. Ravens and Gray Jays (or Canada Jays) were constantly in evidence near the campground - especially the ravens, for they were their usual noisy selves. On the banks of the Clearwater River, a number of Black Terns, Eastern Kingbirds, and four or five nighthawks (busily catching insects during the middle of a sunny afternoon) were noticed within the space of a few hours. Several ravens again kept up a clamor.

According to the local people, mammalian wildlife of many kinds is also plentiful, and this was made evident by sign all along the trail. Snowshoe hares, moose, bear, and lynx are abundant, as are also wolves. Trapping is reported to be usually good during the winter.

Since the trail itself is of considerable historical value, and since it leads through an area of very typical Saskatchewan Boreal Forest with abundant wildlife all around, and into one of the most beautifully scenic river valleys in the province, we would suggest that at least the northern part of the trail, from Rendezvous Lake to the river, should be left untouched by road builders, lumbering interests, or other commercial enterprises. There is probably no immediate danger of the portage being destroyed because there is still no access by road to it, and the winter road that leads to the Clearwater River has been built so that it goes straight north from La Loche, many 
miles to the east of the portage.

This trail, if properly preserved, could easily become a considerable attraction for tourists and residents interested in the history, the forests, the wildlife, and the rugged, unspoiled grandeur of the northern half of this province.

\section{Acknowledgements}

We wish to thank George LeMaigre for information on local game and other animal resources. Thanks are also due Ed Banman and Ken Robertson for help with the maps, and Gus MacAuley, Conservation Officer, who made it possible for us to take aerial photographs of the area. This research trip was supported by the Institute for Northern Studies and by the Department of Anthropology and Archaeology, University of Saskatchewan, Saskatoon.

\section{LITERATURE CITED}

Ells, S. C. 1936. Portage La Loche. Canadian Geographical Journal $12(3): 134-142$.

Kupsch, W. O. 1954. Bituminous sands in the till of the Peter Pond Lake area, Saskatchewan. Department of Mineral Resources, Saskatchewan Geological Survey, Regina.

Mackenzie Alexander (edited by William J. Grant). 1872. Voyages from Montreal through the continent of North America to the Frozen and Pacific Oceans in 1789 and 1793. The Courier Press, Ltd., Toronto.

Turner, J. P. 1943. The La Loche Brigade. The Beaver, December, 1943.

Wettlaufer, B. 1955. The Mortlach Site in the Besant Valley of Saskatchewan. Department of Natural Resources, Anthropological Series No. 1, Regina.

\section{RICHARDSON PONDWEED \\ by J. R. Allan, Lethbridge, Alberta}

The Richardson pondweed, Potamogeton richardsonii, is one of the ten most commonly found, true vascular, bottom-rooted aquatic flowering angiosperms inhabiting the lakes and slow moving streams on the Prairies. The plant, named after its discoverer, Sir John Richardson (1787-1865), was first reported in the American literature in 1905. The pondweeds are members of the genus Potamogeton belonging to the family Zosteraceae and derive their name from the Greek words potamos (a river) and geiton (a neighbor) meaning a river neighbor because of its place of growth. The genus has about 90 species of which 41 are found in North America, the remainder being distributed over much of the north temperate zone. A very few species are common to the shallow oceanic and brackish waters of North America. The various species of Potamogeton are notoriously difficult to identify.

Plants of the family Zosteraceae are of little value except in the conservation of wildlife. The Richardson pondweed is very important from the point of view of fish culture. The foliage is considered of little direct importance as a fish food but indirectly it supports extensive insect life, which in turn is of great value as a fish food. The plant offers shade and shelter as well as a spawning medium for young fish. The seeds, parts of the stems and leaves, and the rootstocks are readily eaten by waterfowl.

The Richardson pondweed is a perennial, aquatic herb that grows completely submerged in the water. Its thin, membranous, oval to lanceolate leaves clasp the stem. The leaves become progressively shorter towards the tip of the plant (Fig. 1A). The leaves have wavy margins and exhibit three to seven prominent veins that tend to run parallel to the long axis of the leaf (Fig. 1B). The leaf stipules are coarse and fibrous and may readily be reduced to shreds.

The flowers are perfect. The spikes are sheathed by stipules in the bud (Fig. 1C) and are elevated to the surface of the water on long stalks (Fig. 1D).

The plant is wind-pollinated and is known to form hybrids occasionally with the white-stem pondweed, Illinois pondweed, variable pondweed, and the largeleaf pondweed. Such hybrids are now being made artificially in the greenhouse at Lethbridge. All these species of pondweed are to be found in Western Canada. The seed 